\title{
COVID-19-related health worries compound the psychiatric distress experienced by families of high-risk infants
}

\author{
Cindy H. Liu ${ }^{1,2,3} \cdot$ Leena Mittal ${ }^{2,3} \cdot$ Carmina Erdei $\oplus^{1,3}$ \\ Received: 21 January 2021 / Revised: 30 January 2021 / Accepted: 4 February 2021 / Published online: 3 March 2021 \\ (c) The Author(s), under exclusive licence to Springer Nature America, Inc. 2021
}

\section{To the Editor:}

Parents of neonatal intensive care unit (NICU) infants are at high risk for perinatal mental health problems, which can impact infant and family outcomes [1]. The COVID-19 pandemic is a major environmental stressor that may compound family psychiatric distress in the NICU, with heightened health-related worries predisposing NICU mothers to exacerbation of mental health issues [2]. This study examines how COVID-19-related health worries might moderate the effect of the NICU experience on maternal mental health symptoms. We tested the hypothesis that NICU parents who endorsed higher levels of COVID-19-related health worries and experiences would report more symptoms of depression, generalized anxiety, and PTSD during the pandemic.

\section{Methods}

This present cross-sectional survey study included mothers who gave birth to healthy and hospitalized infants in the previous 6 months $(N=628$ women: mothers of healthy infants $n=565$, mothers of NICU infants $n=63$ ) from May 19, 2020 to September 23, 2020. Eligible women included those $>18$ years in the United States, who were at least in their second trimester of pregnancy or who had given birth within the past 6 months.

Participants were asked whether their baby required NICU admission, with 0 as "No" and 1 as "Yes," and if

Cindy H. Liu

chliu@bwh.harvard.edu

1 Department of Newborn Medicine, Brigham and Women's Hospital, Boston, MA, USA

2 Department of Psychiatry, Brigham and Women's Hospital, Boston, MA, USA

3 Harvard Medical School, Boston, MA, USA infants were primarily admitted to the NICU for prematurity (born $\leq 37$ gestational weeks) or for other reasons. COVID19-related health worries such as concerns about themselves and their friends and family being infected by the coronavirus from the past 2 weeks were assessed using the Coronavirus Health Impact Survey (CRISIS) [3]. Sum scores of 16 or greater represented "high" levels of worry based on those endorsing "very" to "extremely" on health worries, whereas scores $<16$ represented those at "low" levels of worry based on those endorsing "not at all," "slightly," or "moderately" worried about COVID-19. The UCLA Loneliness Scale Short Form [4] was used. Mental health symptoms were assessed by the Center for Epidemiologic Studies-Depression (CES-D) [5], the Generalized Anxiety Disorder Scale (GAD-7) [6], and the PTSD Checklist-Civilian Version (PCL-C) [7]. Higher sum scores reflected greater severity of experiences.

Covariates included maternal age, race, education, household income, cohabitation with partner, first pregnancy status, and number of life events experienced in the past six months (e.g, severe sickness of close family member, separation or divorce, moving, partner lost job, lost job themselves, increased arguments with partner, financial problems). Other covariates included the Daily Discrimination scale from the Perceived Discrimination Scale [8], and instrumental support through the Two-Way Social Support Scale [9]. Data regarding maternal pre-pregnancy diagnoses of depression, generalized anxiety, or PTSD were collected, as was infant age at the time of survey completion, NICU discharge, or current postmenstrual age for infants still hospitalized in the NICU. Given that experiences may change as a function of time, we controlled for when the participant began the survey relative to the start of the pandemic.

\section{Results}

Table 1 displays sample characteristics and the proportions or mean scores of key psychosocial and mental 
Table 1 Infant and maternal sociodemographic characteristics from the PEACE Study, data collected between May 21, 2020 and September 23, 2020 .

\begin{tabular}{|c|c|c|c|c|}
\hline \multirow[t]{2}{*}{ Predictors } & \multicolumn{3}{|l|}{ Means or $\%$} & \multirow[t]{2}{*}{ Statistical test } \\
\hline & $\begin{array}{l}\text { Overall } \\
(n=628)\end{array}$ & $\begin{array}{l}\text { Non-NICU } \\
(n=565)\end{array}$ & $\begin{array}{l}\text { NICU } \\
(n=63)\end{array}$ & \\
\hline \multicolumn{5}{|l|}{ Infant characteristics } \\
\hline \multicolumn{5}{|l|}{ NICU } \\
\hline No & $90.0 \%$ & & & \\
\hline Yes & $10.0 \%$ & & & \\
\hline \multicolumn{5}{|l|}{ Preterm ( $\leq 37$ weeks) } \\
\hline No & $58.7 \%$ & & & \\
\hline Yes & $41.3 \%$ & & & \\
\hline Child age (weeks) & $\begin{array}{l}M=11.88 \\
\mathrm{SD}=7.37\end{array}$ & $\begin{array}{l}M=11.95 \\
\mathrm{SD}=7.29\end{array}$ & $\begin{array}{l}M=11.27 \\
\mathrm{SD}=8.05\end{array}$ & $\begin{array}{l}t(626)=0.70 \\
p=\mathrm{ns}\end{array}$ \\
\hline \multicolumn{5}{|l|}{ Maternal characteristics } \\
\hline Maternal age (years) & $\begin{array}{l}M=33.55 \\
\mathrm{SD}=3.45\end{array}$ & $\begin{array}{l}M=33.56 \\
\mathrm{SD}=3.47\end{array}$ & $\begin{array}{l}M=33.41 \\
\mathrm{SD}=3.31\end{array}$ & $\begin{array}{l}t(626)=0.74 \\
p=\mathrm{ns}\end{array}$ \\
\hline \multicolumn{5}{|l|}{ Maternal race } \\
\hline White & $89.5 \%$ & $89.2 \%$ & $92.1 \%$ & $\begin{array}{l}\chi^{2}(4)=3.87 \\
p=\mathrm{ns}\end{array}$ \\
\hline Black or African American & $0.5 \%$ & $0.5 \%$ & $0 \%$ & \\
\hline Hispanic or Latino & $4.0 \%$ & $4.2 \%$ & $1.6 \%$ & \\
\hline Asian and Pacific Islander & $3.7 \%$ & $3.9 \%$ & $1.6 \%$ & \\
\hline Other & $2.4 \%$ & $2.1 \%$ & $4.8 \%$ & \\
\hline \multicolumn{5}{|l|}{ Maternal education } \\
\hline Less than college & $7.0 \%$ & $6.0 \%$ & $15.9 \%$ & $\begin{array}{l}\chi^{2}(3)=10.39 \\
p=0.016^{*}\end{array}$ \\
\hline College & $28.7 \%$ & $28.2 \%$ & $33.3 \%$ & \\
\hline Masters & $44.8 \%$ & $45.7 \%$ & $36.5 \%$ & \\
\hline Doctorate & $19.5 \%$ & $20.0 \%$ & $14.3 \%$ & \\
\hline \multicolumn{5}{|l|}{ Household income (USD/year) } \\
\hline$<\$ 74,999$ & $12.1 \%$ & $11.9 \%$ & $14.3 \%$ & $\begin{array}{l}\chi^{2}(3)=3.80 \\
p=\mathrm{ns}\end{array}$ \\
\hline$\$ 75,000-149,999$ & $39.5 \%$ & $38.6 \%$ & $47.6 \%$ & \\
\hline$\$ 150,000-224,999$ & $27.5 \%$ & $27.8 \%$ & $25.4 \%$ & \\
\hline$\geq \$ 225,000$ & $20.9 \%$ & $21.8 \%$ & $12.7 \%$ & \\
\hline \multicolumn{5}{|l|}{ Cohabitating with spouse/partner } \\
\hline Yes & $98.7 \%$ & $98.9 \%$ & $96.8 \%$ & $\begin{array}{l}\chi^{2}(1)=2.01 \\
p=\mathrm{ns}\end{array}$ \\
\hline No & $1.3 \%$ & $1.1 \%$ & $3.2 \%$ & \\
\hline \multicolumn{5}{|l|}{ First pregnancy } \\
\hline Yes & $41.4 \%$ & $41.1 \%$ & $44.4 \%$ & $\begin{array}{l}\chi^{2}(1)=0.27 \\
p=\mathrm{ns}\end{array}$ \\
\hline No & $58.6 \%$ & $58.9 \%$ & $55.6 \%$ & \\
\hline $\begin{array}{l}\text { Days between survey completion } \\
\text { and pandemic start }\end{array}$ & $\begin{array}{l}M=124.22 \\
\mathrm{SD}=30.55\end{array}$ & $\begin{array}{l}M=124.29 \\
\mathrm{SD}=30.38\end{array}$ & $\begin{array}{l}M=123.59 \\
\mathrm{SD}=32.33\end{array}$ & $\begin{array}{l}t(626)=0.17 \\
p=\mathrm{ns}\end{array}$ \\
\hline \multicolumn{5}{|l|}{ COVID-19-related health worries } \\
\hline High & $18.0 \%$ & $17.0 \%$ & $27.0 \%$ & $\begin{array}{l}\chi^{2}(1)=3.84 \\
p=0.05^{\dagger}\end{array}$ \\
\hline Low & $82.0 \%$ & $83.0 \%$ & $73.0 \%$ & \\
\hline
\end{tabular}


Table 1 (continued)

\begin{tabular}{|c|c|c|c|c|}
\hline \multirow[t]{2}{*}{ Predictors } & \multicolumn{3}{|l|}{ Means or $\%$} & \multirow{2}{*}{ Statistical test } \\
\hline & $\begin{array}{l}\text { Overall } \\
(n=628)\end{array}$ & $\begin{array}{l}\text { Non-NICU } \\
(n=565)\end{array}$ & $\begin{array}{l}\text { NICU } \\
(n=63)\end{array}$ & \\
\hline Number of life events (past year) & $\begin{array}{l}M=1.36 \\
\mathrm{SD}=1.36\end{array}$ & $\begin{array}{l}M=1.34 \\
\mathrm{SD}=1.36\end{array}$ & $\begin{array}{l}M=1.52 \\
\mathrm{SD}=1.38\end{array}$ & $\begin{array}{l}t(626)=-1.01 \\
p=\mathrm{ns}\end{array}$ \\
\hline Instrumental social support & $\begin{array}{l}M=17.95 \\
\mathrm{SD}=2.93\end{array}$ & $\begin{array}{l}M=17.96 \\
\mathrm{SD}=2.93\end{array}$ & $\begin{array}{l}M=17.86 \\
\mathrm{SD}=3.03\end{array}$ & $\begin{array}{l}t(626)=0.25 \\
p=\mathrm{ns}\end{array}$ \\
\hline Daily discrimination experiences & $\begin{array}{l}M=31.41 \\
\mathrm{SD}=3.91\end{array}$ & $\begin{array}{l}M=31.36 \\
\mathrm{SD}=3.93\end{array}$ & $\begin{array}{l}M=31.89 \\
\mathrm{SD}=3.65\end{array}$ & $\begin{array}{l}t(626)=-1.03 \\
p=\mathrm{ns}\end{array}$ \\
\hline \multicolumn{5}{|l|}{ Pre-existing mental health diagnosis } \\
\hline Depression & $15.1 \%$ & $13.5 \%$ & $30.2 \%$ & $\begin{array}{l}\chi^{2}(1)=12.32 \\
p<0.001 * * *\end{array}$ \\
\hline Generalized anxiety & $21.5 \%$ & $20.7 \%$ & $28.6 \%$ & $\begin{array}{l}\chi^{2}(1)=2.07 \\
p=\mathrm{ns}\end{array}$ \\
\hline PTSD & $3.8 \%$ & $3.9 \%$ & $3.2 \%$ & $\begin{array}{l}\chi^{2}(1)=0.08 \\
p=\mathrm{ns}\end{array}$ \\
\hline \multicolumn{5}{|l|}{ Mental health symptoms (means) } \\
\hline Depression (CES-D) & $\begin{array}{l}M=13.37 \\
\mathrm{SD}=9.05\end{array}$ & $\begin{array}{l}M=13.17 \\
\mathrm{SD}=8.91\end{array}$ & $\begin{array}{l}M=15.21 \\
\mathrm{SD}=10.11\end{array}$ & $\begin{array}{l}t(617)=-1.68 \\
p=0.09^{\dagger}\end{array}$ \\
\hline Generalized anxiety (GAD-7) & $\begin{array}{l}M=6.47 \\
\mathrm{SD}=5.08\end{array}$ & $\begin{array}{l}M=6.30 \\
\mathrm{SD}=4.97\end{array}$ & $\begin{array}{l}M=8.00 \\
\mathrm{SD}=5.75\end{array}$ & $\begin{array}{l}t(604)=-2.51 \\
p=0.01 *\end{array}$ \\
\hline PTSD (PCL-C) & $\begin{array}{l}M=30.18 \\
\mathrm{SD}=11.16\end{array}$ & $\begin{array}{l}M=29.64 \\
\mathrm{SD}=10.83\end{array}$ & $\begin{array}{l}M=35.17 \\
\mathrm{SD}=12.82\end{array}$ & $\begin{array}{l}t(599)=-3.65 \\
p<0.001 * * *\end{array}$ \\
\hline Loneliness (LS) & $\begin{array}{l}M=5.50 \\
\mathrm{SD}=1.64\end{array}$ & $\begin{array}{l}M=5.50 \\
\mathrm{SD}=1.64\end{array}$ & $\begin{array}{l}M=5.84 \\
\mathrm{SD}=1.83\end{array}$ & $\begin{array}{l}t(623)=-1.71 \\
p=0.09^{\dagger}\end{array}$ \\
\hline
\end{tabular}

${ }^{\dagger} p<0.1, * p<0.05, * * p<0.01, * * * p<0.001$.

Table 2 Adjusted models regressing COVID-19 health worries and NICU admission (prematurity as a primary reason for admission as subanalyses) on maternal depression, anxiety, PTSD, and loneliness, data collected between May 21, 2020 and September $23,2020$.

\begin{tabular}{llll}
\hline & COVID-19 health worries & NICU & COVID-19 health worries $\times$ NICU \\
\hline Depression & $F(1,603)=32.13, p<0.001^{* * *}$ & $F(1,603)=2.54, p=0.112$ & $F(1,603)=32.13, p=0.1^{\dagger}$ \\
Generalized anxiety & $F(1,590)=69.52, p<0.001^{* * *}$ & $F(1,590)=6.90, p=0.009^{* *}$ & $F(1,590)=5.25, p=0.02^{*}$ \\
PTSD & $F(1,585)=27.54, p<0.001^{* * *}$ & $F(1,585)=12.37, p<0.001^{* * *}$ & $F(1,585)=3.10, p=0.08^{\dagger}$ \\
Loneliness & $F(1,609)=13.83, p<0.001^{* * *}$ & $F(1,609)=3.86, p=0.05^{\dagger}$ & $F(1,609)=4.44, p=0.04^{*}$ \\
\hline & COVID-19 health worries & Prematurity & COVID-19 health worries $\times$ prematurity \\
\hline Depression & $F(1,53)=8.77, p=0.005^{* *}$ & $F(1,53)=0.73, p=0.40$ & $F(1,53)=3.30, p=0.08^{\dagger}$ \\
Generalized anxiety & $F(1,54)=29.27, p<0.001^{* * *}$ & $F(1,54)=1.07, p=0.31$ & $F(1,54)=1.18, p=0.28$ \\
PTSD & $F(1,51)=10.29, p=0.002^{* *}$ & $F(1,51)=0.97, p=0.33$ & $F(1,51)=5.34, p=0.03 *$ \\
Loneliness & $F(1,54)=6.79, p=0.012^{*}$ & $F(1,54)=0.67, p=0.42$ & $F(1,54)=0.15, p=0.70$
\end{tabular}

${ }^{\dagger} p<0.1, * p<0.05, * * p<0.01, * * * p<0.001$.

${ }^{a}$ NICU $N$ range: $59-62$, non-NICU $N$ range: $542-563$.

Covariates: pandemic days; child age; maternal age; income; pre-existing diagnosis of depression, generalized anxiety, and PTSD; number of life events; first pregnancy; cohabitation; daily discrimination; instrumental support.

${ }^{\mathrm{b}}$ Admitted for prematurity, $N$ range: $25-26$, Not admitted for prematurity, $N$ range: $34-37$.

Covariates: pandemic days; child age; maternal age; income.

health variables. Table 2 reveals differences in depression, generalized anxiety, PTSD, and loneliness scores based on NICU admission status and prematurity status, and maternal report of either high or low COVID-19-related health worries. Figure 1 (graphs 1-4) shows that a synergistic effect was observed with NICU status showing the largest 


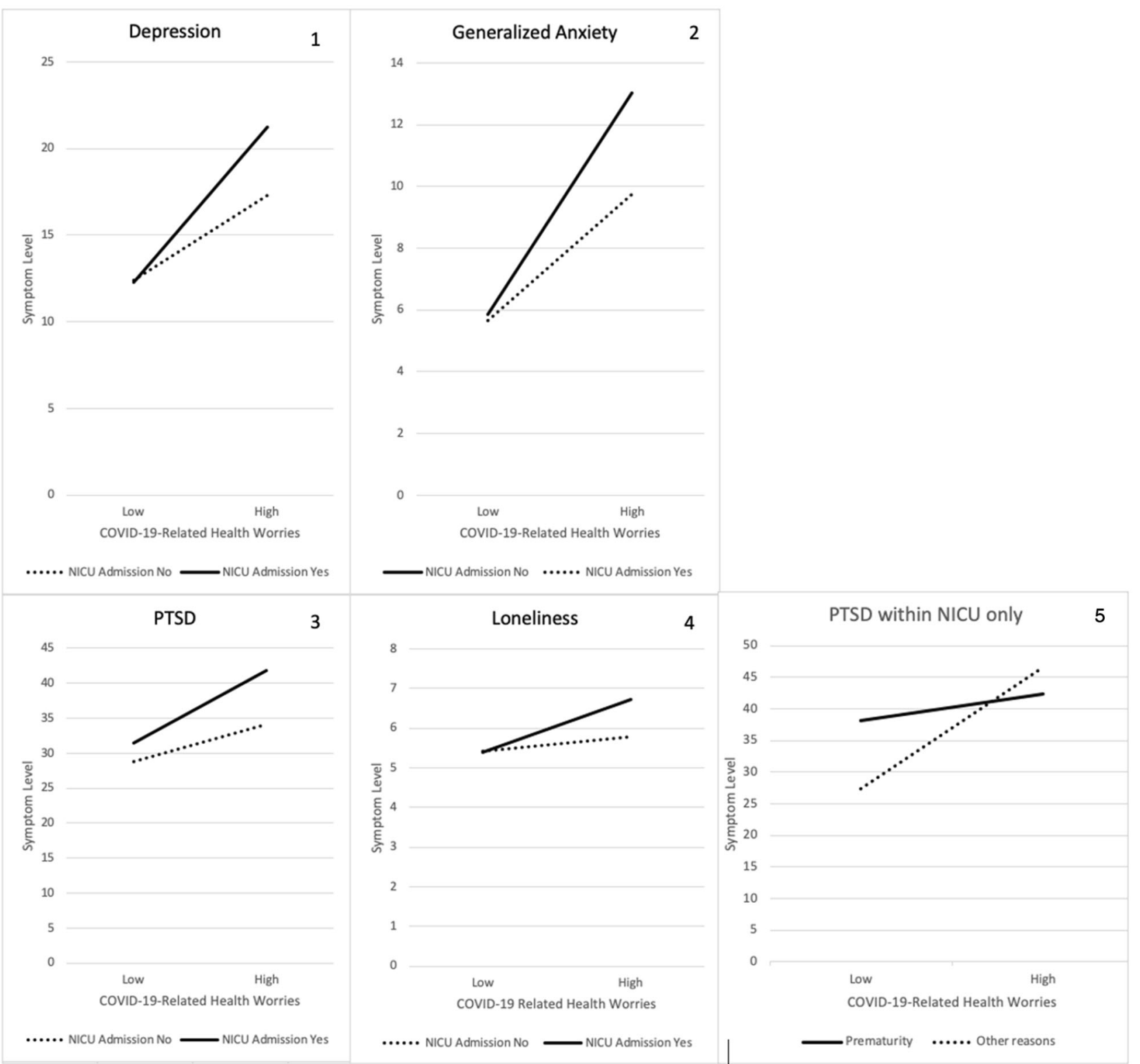

Fig. 1 Mental health symptom levels among mothers of NICU infants experiencing varying levels of COVID-19-related health worries. Graphs 1-4 represent mental health symptom levels by NICU admission (yes/no) and COVID-19-related health worries (low/high) from the PEACE Study in 1-4. Graph 5 represents PTSD symptom levels by NICU admission reasons (premature/other) and COVID-19related health worries (low/high), data collected between May 21, 2020 and September 23, 2020. effect on depression, generalized anxiety, and loneliness outcomes for those mothers who reported high COVID-19related health worries. Post-hoc $t$-tests indicated that NICU parents reported significantly higher symptoms of anxiety and PTSD $(p<0.05)$. Group differences in the remaining outcomes did not achieve statistical significance (depression: $p=0.13$; loneliness: $p=0.09$ ).

We also explored how mental health outcomes differed based on infants primarily admitted to the NICU for prematurity (versus admitted for other reasons), and COVID-19-related health worries. Among the 63 infants admitted to the NICU whose mothers responded to the survey, the largest subgroup comprised of 26 infants (41\%) admitted due to prematurity, i.e., birth before 37 weeks of gestation. For the remainder of NICU infants, $17(27 \%)$ were admitted for respiratory issues, 9 (14\%) for hypoglycemia, and $11(17 \%)$ for other reasons per parental report. The main effect of COVID-19-related health worries was moderated by NICU admission for prematurity, but only for PTSD symptoms. Post-hoc $t$-tests indicated elevated PTSD scores among parents of NICU infants admitted for reasons other than prematurity, and who scored high on COVID-19-related health worries $(p<0.001)$. The remainder of the within-NICU subgroups 
were too small to permit observation of significant differences.

\section{Discussion}

The NICU mothers who report being "very worried" about the potential health implications from COVID-19 are more likely to experience symptoms of depression, generalized anxiety, and feelings of loneliness. The data presented here provide evidence of the COVID-19 pandemic as a major environmental stressor that does not just have an additive effect [10], but rather, compounds the already high levels of psychiatric distress experienced by families of infants in the NICU.

A closer examination of our NICU sample shows that COVID-19-related health worries are more robustly associated with mental health symptoms among NICU mothers whose infants were hospitalized for reasons other than prematurity (most commonly transient respiratory problems and hypoglycemia). The unexpected nature of these medical conditions and need for an unplanned NICU hospitalization may be perceived as traumatic, increasing the risk for trauma-related symptoms. Despite our small NICU subgroup samples and limited details regarding infant hospital courses, these data support the recent call for enhanced psychosocial support of all families of high-risk infants [10], including infants who unexpectedly require NICU hospitalization for milder or transient conditions. Moreover, NICU parents with subclinical anxiety might develop clinically significant symptoms when also experiencing a major environmental stressor [11], an aspect that deserves further attention. Universal mental health screening and enhanced support of NICU families have previously been called for [12]; this becomes even more salient in light of these findings [10], with a need for interventions that employ a multilayered and collaborative approach between maternal health providers, mental health providers, NICU professionals, and pediatricians. Providers should also consider the impact of compounded stress on maternal-infant bonding given the existing challenges many NICU mothers encounter in establishing an emotional connection with their infant [13].

Acknowledgements We are grateful to the Mary A. Tynan Faculty Fellowship, the Weinberg and Barton families, the Family Health and Resiliency Fund, and a NIMH K23 MH 107714-01 A1 award (to CHL), and Ga Tin Fifi Wong, Emily Zhang, and Sunah Hyun for their role in the data collection.
Author contributions CHL designed the study, analyzed the data, and wrote the manuscript. LM provided input to the interpretation of findings. CE provided input to the analyses, its interpretation, and contributed to the manuscript writing.

\section{Compliance with ethical standards}

Conflict of interest The authors declare no competing interests.

Publisher's note Springer Nature remains neutral with regard to jurisdictional claims in published maps and institutional affiliations.

\section{References}

1. Huhtala M, Korja R, Lehtonen L, Haataja L, Lapinleimu H, Rautava P, et al. Parental psychological well-being and behavioral outcome of very low birth weight infants at 3 years. Pediatrics. 2012;129(Apr):e937-44.

2. Erdei C, Liu CH. The downstream effects of COVID-19: a call for supporting family wellbeing in the NICU. J Perinatol. 2020;40 (Sep):1283-5.

3. Merikangas K, Milham M, Stringaris A. The Coronavirus Health Impact Survey (CRISIS); 2020. Available from: http://www. crisissurvey.org/

4. Russell D, Peplau LA, Cutrona CE. The revised UCLA Loneliness Scale: concurrent and discriminant validity evidence. J Personal Soc Psychol. 1980;39(Sep):472-80.

5. Radloff LS. The CES-D scale: a self-report depression scale for research in the general population. Appl Psychological Meas. 1977; (Jun):385-401.

6. Spitzer RL, Kroenke K, Williams JB, Löwe B. A brief measure for assessing generalized anxiety disorder: the GAD-7. Arch Intern Med. 2006;166:1092-7.

7. Weathers FW, Litz BT, Herman DS, Huska JA, Keane TM. The PTSD checklist (PCL): reliability, validity, and diagnostic utility. San Antonio, TX: Annual Convention of the International Society for Traumatic Stress Studies; 1993.

8. Williams DR, Yu Y, Jackson JS, Anderson NB. Racial differences in physical and mental health: socio-economic status, stress and discrimination. J Health Psychol. 1997;2(Jul):335-51.

9. Shakespeare-Finch J, Obst PL. The development of the 2-way social support scale: a measure of giving and receiving emotional and instrumental support. J Personal Assess. 2011;93(Oct):483-90.

10. Lemmon ME, Chapman I, Malcolm W, Kelley K, Shaw RJ, Milazzo A, et al. Beyond the first wave: consequences of COVID19 on high-risk infants and families. Am J Perinatol. 2020;37:1283.

11. Havranek MM, Bolliger B, Roos S, Pryce CR, Quednow BB, Seifritz E. Uncontrollable and unpredictable stress interacts with subclinical depression and anxiety scores in determining anxiety response. Stress. 2016;19:53-62.

12. Erdei C, Liu CH, Machie M, Church PT, Heyne R. Parent mental health and neurodevelopmental outcomes of children hospitalized in the neonatal intensive care unit. Early Hum Dev. 2021;154:105278.

13. Medina IMF, Granero-Molina J, Fernández-Sola C, HernándezPadilla JM, Ávila MC, Rodríguez M, et al. Bonding in neonatal intensive care units: experiences of extremely preterm infants' mothers. Women Birth. 2018;31:325-30. 